\title{
Determination of Endodormancy Break in Almond Flower Buds by a Correlation Model Using the Average Temperature of Different Day Intervals and its Application to the Estimation of Chill and Heat Requirements and Blooming Date
}

\author{
J.M. Alonso, J.M. Ansón, M.T. Espiau, and R. Socias i Company ${ }^{1}$ \\ Unidad de Fruticultura, Centro de Investigación y Tecnología Agroalimentaria, DGA, Apartado 727, \\ 50080 Zaragoza, Spain
}

\begin{abstract}
AdDitional INDEX wORDS. Prunus amygdalus, endodormancy, dormancy breaking, ecodormancy
Abstract. Almond (Prunus amygdalus Batsch.) blooming date is determined by the temperatures during the dormancy period, from the onset of endodormancy to just before blooming. In this work we have developed a model, based on several years data, to estimate the mean transition date from endodormancy to ecodormancy in 44 almond cultivars covering the whole range of almond bloom, through the significance of correlation coefficients between the temperatures occurring during dormancy and the date of full bloom. The estimation of this date for each cultivar has allowed the calculation of its chill and heat requirements. It was found that most cultivars have chilling requirements between 400 and 600 chill units, whereas the span of heat requirements was wider, from 5500 to 9300 growing degree hours Celsius. Some cultivars show high chilling requirements and low heat requirements whereas others show opposite requirements. These differences confirm the wide almond adaptability to different climatic conditions and offer the possibility of being utilized in breeding programs. The good fit shown by the application of this model in the prediction of bloom time may sustain its application in chilling and heat requirement estimation in other fruit species if blooming dates and climatic data for several years are available.
\end{abstract}

Almond cultivars probably show the widest range of blooming dates among all the fruit and nut species (Socias i Company and Felipe, 1992). Blooming date is considered dependent on the winter progression of temperatures affecting the different stages of dormancy (Lang et al., 1987). However, the sequence of blooming of the different almond cultivars is maintained over the years with small shifts (Felipe, 1977).

At dormancy onset, flower organogenesis is complete (Lamp et al., 2001). During endodormancy, bud growth is hardly perceptible, although constant. After accumulating enough chilling, endodormancy concludes giving its way to ecodormancy. At this later stage, flower bud growth mostly depends on heat accumulation, so that bud growth speed increases considerably due to the usual favorable warm temperatures (Kester and Gradziel, 1996; Westwood, 1978). The end of ecodormancy is considered at $F^{50}$, anthesis of $50 \%$ of the flowers (Tabuenca et al., 1972). This common behavior has been observed in other species of the genus Prunus L. (Andrés and Durán, 1999; Ashcroft et al., 1977; Guerriero et al., 2002; Richardson et al., 1974, 1975; Tabuenca, 1980).

To estimate the chill and heat requirements of any cultivar, besides temperature data, three chronological dates must be fixed: the chill accumulation start date, the endodormancy breaking date

Received for publication 23 June 2004. Accepted for publication 11 Aug. 2004. Research conducted under the Spanish projects CICYT AGL2001-1054-C03-02 and INIA RF02-001. J.M. Alonso acknowledges a scholarship grant from the Instituto Nacional de Investigación y Tecnología Agraria y Alimentaria (INIA). We highly appreciate the comments of and the support from Dr. A.J. Felipe, founder of the almond collection of this study, and of Dr. M.C. Tabuenca, who studied the first temperature requirements in almond.

'Corresponding author; e-mail address: rsocias@aragon.es and the $F^{50}$ date. The first date was fixed by the last negative daily accumulation of chill units (CU) and the $F^{50}$ date (ecodormancy end) by visual observation in the field. Unfortunately, there is no way to infer the endodormancy breaking date from any temperature or phenological observation. However, this date is essential for chill and heat requirement estimations because calculations are made until or from that date.

Low temperatures are the most significant factor affecting endodormancy completion, but other climatic factors such as heat, light intensity, and mist may also affect to a certain extent endodormancy evolution (Freeman and Martin, 1981). Traditionally, determination of endodormancy end was carried out by stressing the plant material by temperature and photoperiod changes, like comparing the flower bud dry weight difference between the field and on sticks staying several days in a warm chamber (Brown and Abi-Fadel, 1953; Brown and Kotob, 1957). However, not only a precise determination of the thermic requirements for breaking dormancy is nearly impossible under field conditions, but also under laboratory conditions it must be considered with caution (Dennis, 2003). Besides, chill and heat requirements were shown to be interdependent processes. Thus, if chill accumulation was too low, there was an increase of heat accumulation, and vice versa (Couvillon and Erez, 1985), making the estimations based in one year data very imprecise (Tabuenca, 1975).

Ashcroft etal. (1977) put forward a statistical method to estimate chill and heat requirements using only field data: full bloom dates and previous temperatures for several seasons. In this method, the chill requirement selected for a cultivar was that giving the lowest variation coefficient for the growing degree hours generated for this cultivar with that chill requirement. However, in this method, dissimilar chill requirements may generate growing degree hours 
with similar variation coefficients, making a difficult chill and heat requirement choice. Furthermore, it did not consider the endodormancy end date.

In almond, only a few reports have dealt with the evaluation of chill and heat requirements, using different methods and systems of quantification. The first estimates of chilling were quantified as the number of hours under $7{ }^{\circ} \mathrm{C}$ by the establishment of the endodormancy breaking date by the dry weight evolution method, in only a few cultivars and local Spanish clones (Tabuenca, 1972). Heat requirements were measured as the addition of maximum and minimum daily temperatures (Tabuenca et al., 1972). Later, Rattigan and Hill (1986) applied in almond the method of Ashcroft et al. (1977) and evaluated the chilling and heat requirements of 12 almond cultivars grown in the mild winter climate of Australia and also observed the influence of different locations on the blooming behavior of three cultivars (Rattigan and Hill, 1987). More recently, the chilling and heat requirements of 10 almond cultivars and breeding selections grown in the mild winter climate of southeastern Spain have also been reported by the assess of endodormacy breaking date by the bud weight method (Egea et al., 2003).

Unfortunately, the pioneering work of M.C. Tabuenca was not continued and it is appealing that it was done in the same place and on the collection originating the actual one. Thus, our objective was the application and validation of a method to estimate the mean date of endodormancy to ecodormancy transition avoiding the problems and shortcomings of the method of bud weighting in a single year. Consequently, in the present work, field data from several years for 44 almond cultivars grown in the cold winter conditions of the Ebro Central Valley were analyzed, establishing the transition date from endodormancy to ecodormancy on orchard data and explaining the behavior of each cultivar under its actual environment. From this mean date, chilling and heat requirements can be calculated from the average temperature data of these same years.

\section{Materials and Methods}

Plant material and data collection. The data on blooming dates to develop the model were collected for 44 almond cultivars from a wide geographical origin (Table 1). Each cultivar was represented by three trees grafted on the peach [Prunus persica (L.) Batsch.] seedling rootstock GF 305 in the Spanish National Almond Germplasm Collection located at the Centro de Investigación y Tecnología Agroalimentaria de Aragón. The age of the trees ranged from 10 to 14 years at the beginning of the study. This Center is located at lat. $41^{\circ} 38^{\prime} 50^{\prime \prime} \mathrm{N}$ and long. $0^{\circ} 53^{\prime} 07^{\prime \prime} \mathrm{W}$, at 220 mover sea level, with an average annual rainfall of $328.5 \mathrm{~mm}$ and average annual temperatures of 8.5 ${ }^{\circ} \mathrm{C}$ (minimum), $14.5^{\circ} \mathrm{C}$ (medium) and $20.6^{\circ} \mathrm{C}$ (maximum). The date of anthesis for $50 \%$ of the flowers $\left(F^{50}\right)$, considered the end of ecodormancy (Couvillon and Erez, 1985), was recorded for the three trees during the blooming seasons from 1994 to 2000 to develop the method and in 2002 to validate it. The data on daily maximum, minimum and mean temperatures were obtained from a me- teorological station placed in a nearby plot, using only the data from the months previous to bloom, from October to March for the same seasons.

DEVELOPMENT OF THE METHOD TO ASSESS ENDODORMANCY TO ECODORMANCY TRANSITION. The method was based on the different effect of cold and warm temperatures on the time of full bloom date depending on its incidence during endodormancy or ecododormancy (Tabuenca and Herrero, 1966; Tabuenca et al., 1972). During endodormancy, cold temperatures would advance blooming, whereas warm temperatures would have no effect. On the contrary, during ecodormancy, temperatures produce the opposite effect, so warm temperatures advance blooming date by favoring flower bud development, once chill accumulation is fulfilled, and cold temperatures produce a delay of blooming by a retard in flower bud development. The transition from one to the other dormancy stage may be related to the relationship between the average daily temperatures registered in any time period during dormancy and the cultivar flowering dates.

To develop the method, one matrix of blooming dates and 18 temperature matrices were designed (Fig. 1). The blooming date matrix was defined by two axes: the columns by the years, from 1994 to 2000; and the rows by the cultivar, in alphabetical order, from 'Aii' to 'Zahaf'. Each temperature matrix was also defined by two axes: the columns by the same years, from 1994 to 2000; and the rows by the calendar day from 1 Oct. (day 1) to $28 \mathrm{Feb}$. (day 179). The data (Table 2) introduced in each temperature matrix cell was the average of one of the three different daily temperatures ( $T=$ mean, $T m=$ minimum and $T M=$ maximum) measured during periods $(p)$ of different length, ranging from 5 to $30 \mathrm{~d}$ with increments of $5 \mathrm{~d}$. For any date and period, the temperatures recorded were those of the $p$ days counting from that calendar day. Thus, for 1 Oct. 1994, a period of $5 \mathrm{~d}$ and the mean daily temperature, the data included was the average from $T_{1 \text { Oct. 1994 }}$ to $T_{5 \text { Oct. 1994 }}$; for 2 Oct. 1994, the same period of $5 \mathrm{~d}$, and the mean daily temperatures, the data introduced was the average from $T_{2 \text { Oct. } 1994}$ to $T_{6 \text { Oct. 1994; }}$, and so on.

Eighteen vectors were obtained for each day from these 18 matrices, each vector including seven values, one corresponding to every year. The 18 vectors of each day were correlated to the vector of the blooming dates of each cultivar $\left(\mathrm{F}^{50}{ }_{v y}\right)$ by calculating the Pearson coefficients between these two vectors $(r)$. By this correlation, it is possible to ascertain the influence of the temperature of the days following this date on the blooming date. The significance of these correlation coefficients points to the strength of this correlation, thus allowing to estimate the date after which temperatures advance bloom and, consequently, the
Table 1. Origin of the almond cultivars studied.

\begin{tabular}{ll}
$\begin{array}{l}\text { Country } \\
\text { of origin }\end{array}$ & \multicolumn{1}{c}{ Cultivar } \\
\hline Australia & Chellastone \\
France & Aï, Ferragnès, Fournat de Brézenaud, Lauranne, Tardive de la Verdière \\
Italy & Cristomorto, Filippo Ceo, Picantilli, Rachele, Tuono \\
Spain & Alzina, Aylés, Bertina, Blanquerna, Cambra, Desmayo Largueta, \\
& Desmayo Rojo, Felisia, Guara, Jordi, Marcona, Masbovera, Moncayo, \\
& Ponç, Pou de Felanitx, Ramillete, Rof, Totsol, Verdereta, Vivot, Xina \\
Tunisia & Constantini, Zahaf \\
Ucraina & Miagkoskorlupyj, Primorskij, Yaltinskij \\
USA & LeGrand, Nec Plus Ultra, Nonpareil, Texas, Thompson, Titan, Tokyo \\
\hline
\end{tabular}




\section{Blooming dates matrix}

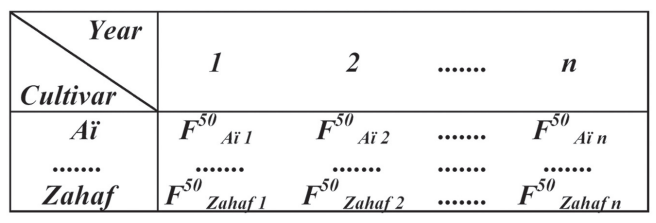

Temperature matrices

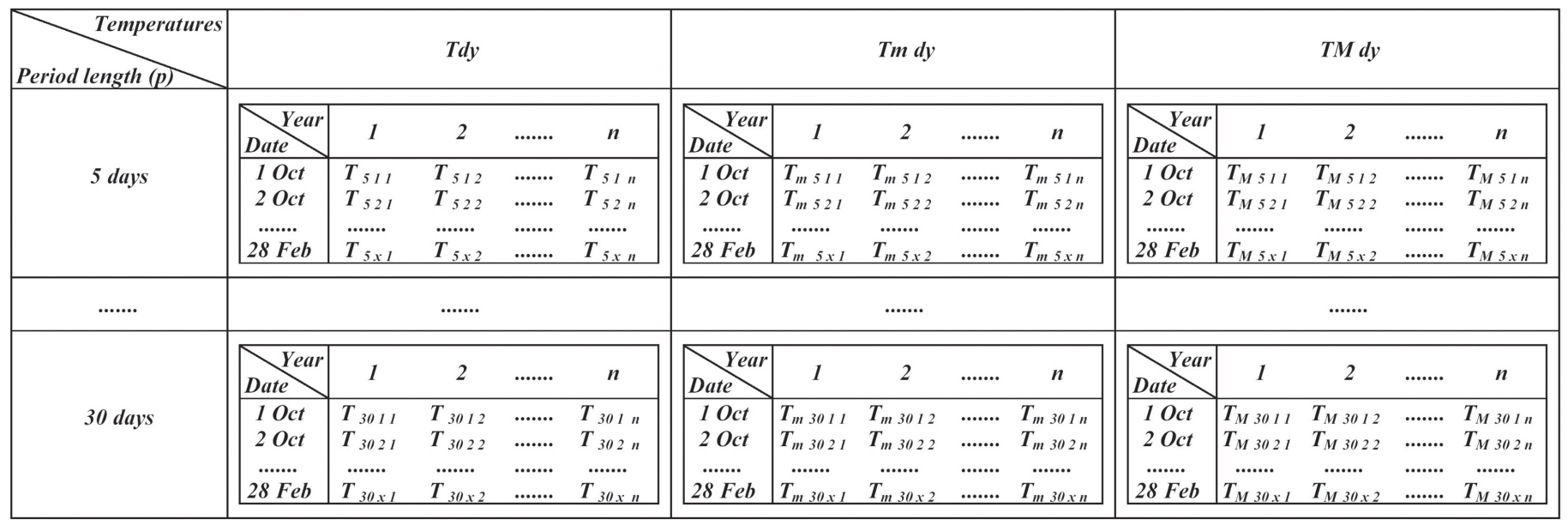

\section{Calculation of Pearson correlation coefficients}

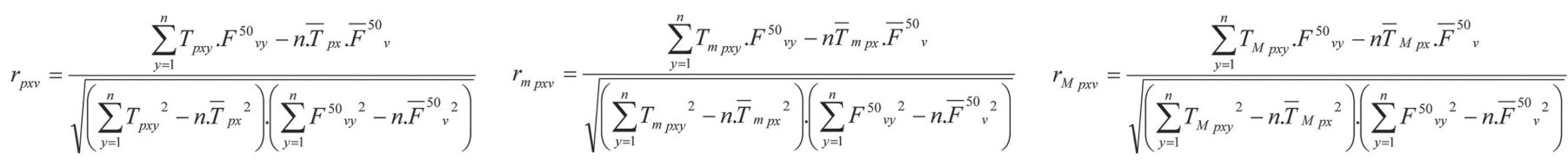

being:

$$
\bar{F}_{v}^{50}=\frac{\sum_{y=1}^{n} F^{50}{ }_{v y}}{n} \quad \bar{T}_{p d}=\frac{\sum_{y=1}^{n} T_{p d y}}{n} \quad \bar{T}_{m p d}=\frac{\sum_{y=1}^{n} T_{m p d y}}{n} \quad \bar{T}_{M p d}=\frac{\sum_{y=1}^{n} T_{M p d y}}{n}
$$

Fig. 1. Mathematical development of the method through the establishment of the blooming date matrix and the temperature matrices. The Pearson correlation coefficients are obtained by comparing the vectors of these two types of matrices.

\begin{tabular}{|c|c|c|}
\hline Symbol & Meaning & Unit \\
\hline$y$ & Year & \\
\hline$p$ & Length of the period considered for averaging temperatures & days \\
\hline$d$ & Date & days from 1 Oct. \\
\hline$x$ & End date of the analysis (in our case 28 Feb. $=179 \mathrm{~d}$ ) & days from 1 Oct. \\
\hline$F^{50}{ }_{v y}$ & Date in which cultivar $v$ shows $50 \%$ of the flowers at anthesis in the year $y$ & days from 1 Oct. \\
\hline $\bar{F}^{50}{ }_{v}$ & Mean of $F^{50}{ }_{v y}$ for the cultivar $v$ & days from 1 Oct. \\
\hline$T_{d y}$ & Daily mean temperature for the day $d$ in the year $y$ & ${ }^{\circ} \mathrm{C}$ \\
\hline$T_{m d y}$ & Daily minimum temperature for the day $d$ in the year $y$ & ${ }^{\circ} \mathrm{C}$ \\
\hline$T_{M d y}$ & Daily maximum temperature for the day $d$ in the year $y$ & ${ }^{\circ} \mathrm{C}$ \\
\hline$T_{p d y}$ & Mean of daily mean temperatures for the $p$ period following day $d$ in year $y$ & ${ }^{\circ} \mathrm{C}$ \\
\hline$T_{m p d y}$ & Mean of daily minimum temperatures for the $p$ period following day $d$ in year $y$ & ${ }^{\circ} \mathrm{C}$ \\
\hline$T_{M p d y}$ & Mean of daily maximum temperatures for the $p$ period following day $d$ in year $y$ & ${ }^{\circ} \mathrm{C}$ \\
\hline $\bar{T}_{p d}$ & Mean of the $T_{p d y}$ for day $d$ and period $p$ for the years studied & ${ }^{\circ} \mathrm{C}$ \\
\hline $\bar{T}_{m p d}$ & Mean of the $T_{m p d y}$ for day $d$ and period $p$ for the years studied & ${ }^{\circ} \mathrm{C}$ \\
\hline $\bar{T}_{M p d}$ & Mean of the $T_{M p d y}$ for day $d$ and period $p$ for the years studied & ${ }^{\circ} \mathrm{C}$ \\
\hline$r_{p d v}$ & Pearson correlation coefficient for day $d$, period $p$, and cultivar $v$ between $T_{p d y}$ and $F^{50}{ }_{v y}$. & \\
\hline$r_{m p d v}$ & Pearson correlation coefficient for day $d$, period $p$, and cultivar $v$ between $T_{m p d y}$ and $F^{50}{ }_{v y}$. & \\
\hline$r_{M p d v}$ & Pearson correlation coefficient for day $d$, period $p$, and cultivar $v$ between $T_{M p d y}$ and $F^{50}{ }_{v y}$. & \\
\hline
\end{tabular}

Table. 2. Symbols of the method as described in the text. 
date on which chilling requirement has been wholly satisfied and ecodormancy has began.

As correlations were obtained with a set of data from 7 years, correlation coefficients higher than +0.754 or lower than -0.754 are statistitically significant (Hoshmand, 1988) with the Student $t$ test for $5 \mathrm{df}$ and a two-tailed test at $\alpha=0.05$. Consequently, the endodormancy to ecodormancy transition was considered to be when correlation coefficients change from being mainly positive to be mainly negative. The end of this transition period, coincident with endodormancy breaking, was considered to be given by the first significant coefficient in a continued presence of negative coefficients.

Chilling and heat ReQuirement calculation. Hourly temperatures were estimated from the daily maximum and minimum values according to the lineal approach developed by Richardson et al. (1974) between 1 Oct. and 31 Mar. for the seven seasons. Chilling requirements were estimated in $\mathrm{CU}$, giving to each hour the value in function of the rate for each temperature range $(<1.4$ ${ }^{\circ} \mathrm{C}=0 ; 1.5$ to $2.4{ }^{\circ} \mathrm{C}=0.5 ; 2.5$ to $9.1{ }^{\circ} \mathrm{C}=1 ; 9.2$ to $12.4{ }^{\circ} \mathrm{C}=$ $0.5 ; 12.5$ to $15.9^{\circ} \mathrm{C}=0 ; 16$ to $18^{\circ} \mathrm{C}=-0.5 ;>18^{\circ} \mathrm{C}=-1$ ). Every season, the first day of chilling accumulation was considered to be the day after the last negative CU accumulation, as from this date on there will be no negation of chilling for the whole day (Richardson et al., 1974). Thus, chilling accumulation was computed every season from a different date depending on the registered temperatures. From that date until the transition date estimated with the model here developed, CU accumulation was computed for every season and the mean was considered to be the chilling requirement of each cultivar. The mean date for starting chilling accumulation was 26 Oct.

Heat requirements were estimated as the mean of growing degree hour Celsius (GDH) accumulation (Richardson et al., $1975)$, from the transition date estimated until full bloom date $\left(F^{50}\right)$ of each cultivar for the seven seasons. One GDH is defined as $1 \mathrm{~h}$ at a temperature $1^{\circ} \mathrm{C}$ above the base temperature of $4.5^{\circ} \mathrm{C}$. The GDH are calculated by subtracting $4.5^{\circ} \mathrm{C}$ from each hourly temperature between 4.5 and $25^{\circ} \mathrm{C}$. All temperatures above 25 ${ }^{\circ} \mathrm{C}$ are assumed to equal $25^{\circ} \mathrm{C}$; thus the greatest accumulation for any hour is $20.5 \mathrm{GDH}$.

VALIDATION OF THE MODEL. The theoretical blooming date for the 44 cultivars was calculated in 2002 according to the chilling and heat requirements obtained in the model and the temperature data measured during the 2001-02 season, taking the values of CU and GDH of the day giving the closest values to those obtained from the method. A linear regression without intercept (Kleijnen, 1999) was obtained between these theoretical dates and the actual dates observed during the 2002 blooming season, both measured as days from 1 Oct.

\section{Results and Discussion}

Development OF THE MODEL. The histograms of the correlation coefficients for each of the six length periods considered are shown in Fig. 2 for 'Nonpareil'. Several assumptions on the sign of the coefficients must be pointed out for their interpretation. Positive correlation coefficients were obtained on the earlier dates, when endodormancy is assumed to start. A positive correlation coefficient on a certain date means that a temperature increase during the considered subsequent period entails an increase of the span until bloom. Negative coefficients must appear when ecodormany would already be established and buds accumulate heat. Thus, low temperatures produce a slower heat accumulation, decrease bud development and delay the bloom date.

Usually the correlation coefficients obtained with the three daily temperatures $(T, T m$, and $T M$ ) have the same sign but their magnitudes differ. The size and the number of significant coefficients were higher when using the daily mean and maximum temperatures ( $T$ and $T M$ ) and lower when using the minimum daily temperatures $(\mathrm{Tm})$. As a consequence, to estimate endodormancy breaking, only the correlation coefficients obtained with the mean daily temperatures $(T)$ were taken into account, likewise considering that these temperatures are more representative of the actual daily temperature.

The period length affects the value of the correlation coefficients and how they change from negative to positive. Thus, the longer the period, the less sign changes were observed. The smoother evolution observed with longer periods may be explained by the lesser weight of extreme occasional temperatures occurring during those periods. Furthermore, the longer the period, the lower the correlation coefficients, it being possible not to find any significant coefficient for the $30 \mathrm{~d}$ period in most cultivars, as shown for 'Nonpareil' in Fig. 2F, difficulting the determination of endodormancy to ecodormancy transition. Thus, for the ensemble of all the cultivars studied, the periods of 15 and 20 $\mathrm{d}$ generate the largest amount of significant coefficients, the periods of 10 and $25 \mathrm{~d}$ a smaller amount, and the period of $30 \mathrm{~d}$ hardly any significant coefficient. As a result, the period of $15 \mathrm{~d}$ was considered the optimum to estimate endodormancy breaking (Fig. 2C and 3). Besides, this period generated significant coefficients in all cultivars, as shown in Fig. 3 for another six representative cultivars.

As a consequence, the best estimation for endodormancy to ecodormancy transition may be considered to be the first day when a significant negative correlation coefficient was obtained with a period of $15 \mathrm{~d}$ and the mean daily temperatures. Undoubtedly, negative correlation coefficients were already observed in the previous days, but the significance of the correlation coefficients for this date certainly implies that low temperatures retard blooming in this cultivar from that date on and, consequently, ecodormancy has started. With this assumption, the endodormancy to ecodormancy transition date for the ensemble of the almond cultivars in Zaragoza, ranges from 28 Nov. to 5 Dec. (Table 3), a span of only one week, with most of the cultivars grouped on 2, 3, and 4 Dec.

This small span of days can be explained because the transition for endodormancy to ecodormancy was estimated by the mean behavior during seven years, as opposed to the classical bud weight method, mostly done in a single year and with manipulation of plant material, taken suddenly from a natural environment to an artificial one, and giving unreliable results (Tabuenca, 1975). However, the model developed here allows the mean date of endodormancy to ecodormancy transition to be obtained by the observation of whole trees in their actual environment during several seasons.

Chilling AND heat ReQuirements. Once the mean date of endodormancy breaking was estimated for each cultivar, chilling and heat requirements were calculated according to the Utah model (Richardson et al., 1974, 1975). In the climatic conditions of Zaragoza, the almond chilling requirements range between 350 and $500 \mathrm{CU}$ (Table 3 ). The first cultivars to break endodormancy were those with the lowest chilling requirements, including 'Tardive de la Verdière' (358 CU), 'Rachele' (376 CU), 'Zahaf' and 'Pou de Felanitx' (392 CU), and 'Xina' and 'Nonpareil' (403 CU), which at the end of November have already fulfilled their chilling 

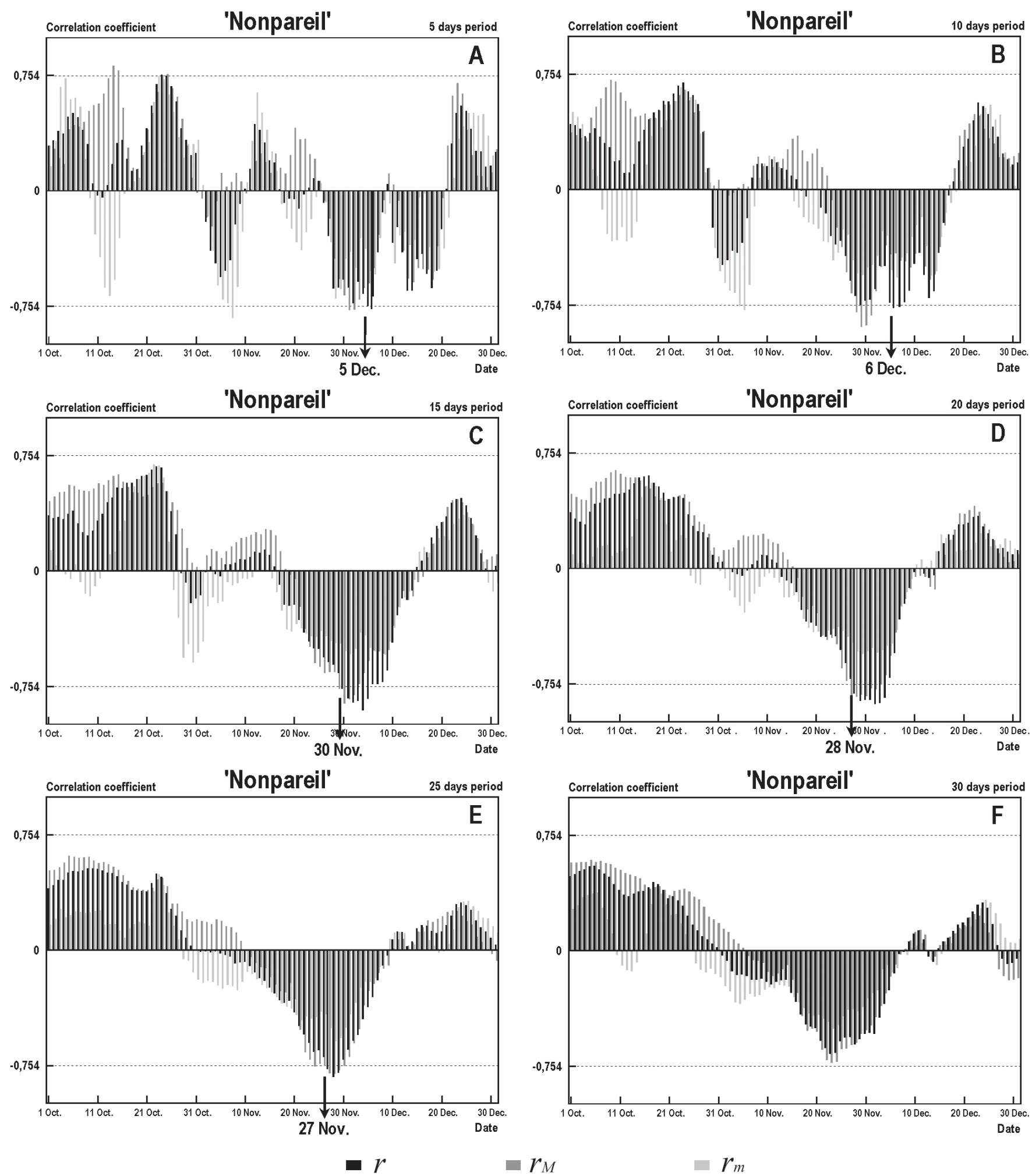

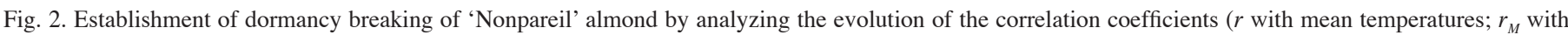

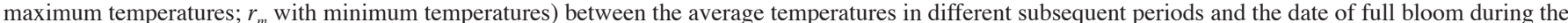

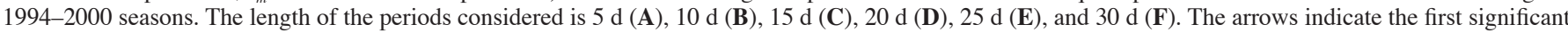
correlation coefficient obtained with the mean temperature and, thus, endodormancy breaking. 

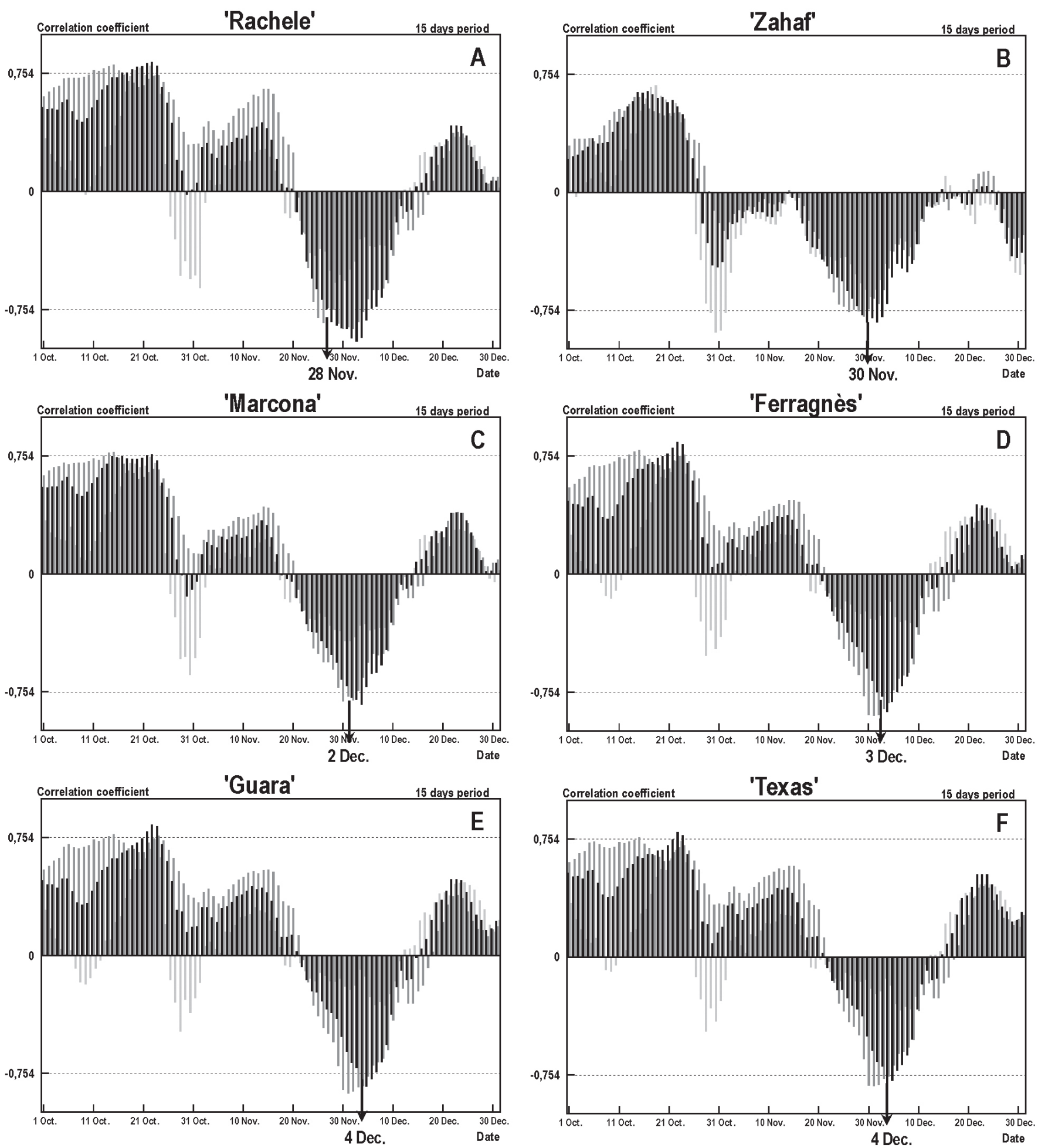

$r$

$r_{M}$

- $r_{m}$

Fig. 3. Graphical representation of the correlation coefficients ( $r$ with mean temperatures; $r_{u}$ with maximum temperatures; $r$ with minimum temperatures) of average temperatures for 15-d periods and dormancy breaking establishment of several almond cultivars by significant coefficients. (A) 'Rachele', (B) 'Zahaf', (C) 'Marcona', (D) 'Ferragnès', (E) 'Guara', (F) 'Texas'. The arrows indicate the first significant correlation coefficient obtained with the mean temperature and, thus, endodormancy breaking. 
Table 3. Chilling and heat requirements calculated by the application of the method during the period of 1994 to 2000 for the almond cultivars studied.

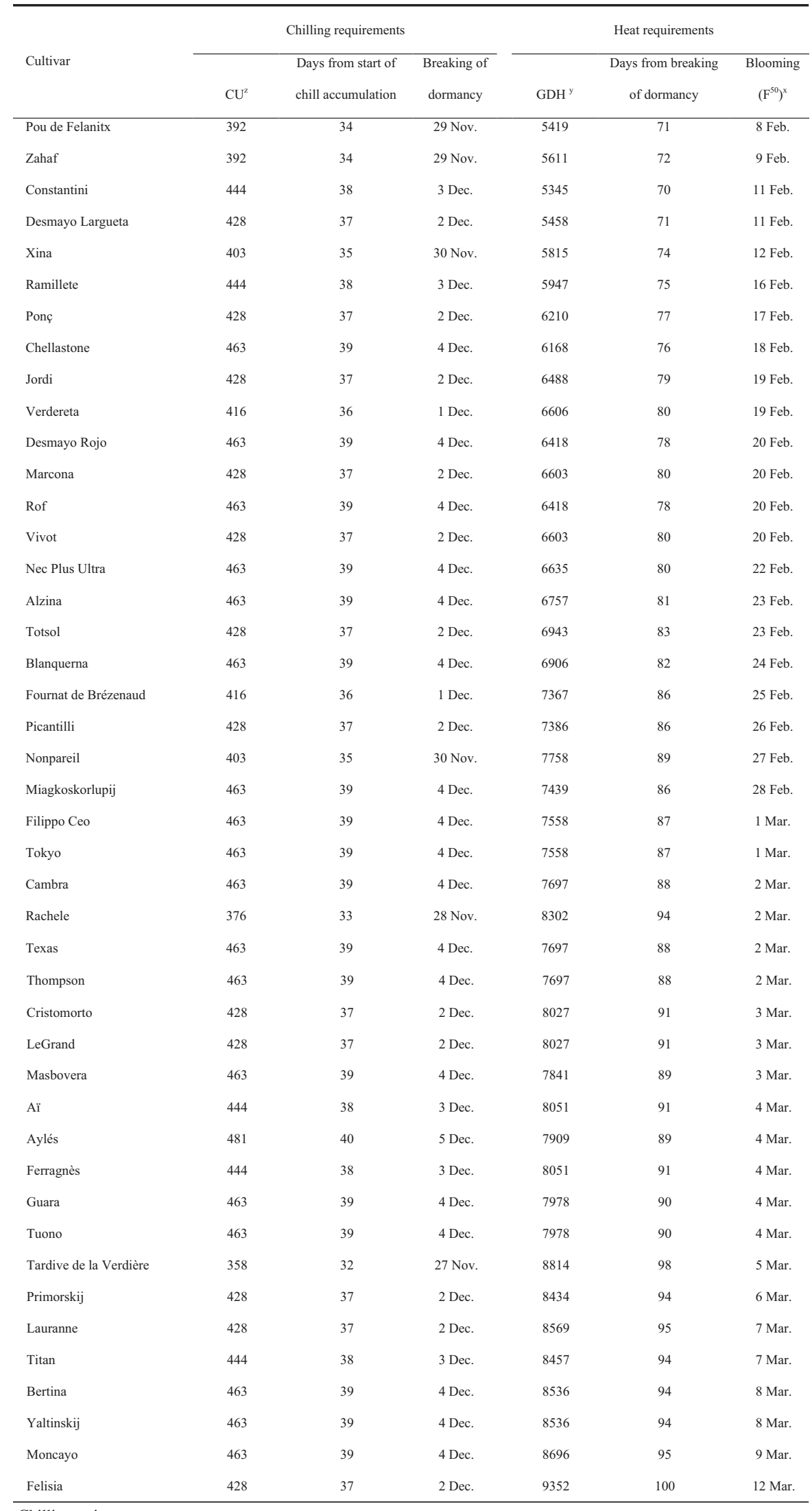

zChilling units.

yGrowing degree hours in degrees Celsius.

Mean date for full blooming (anthesis of $50 \%$ of the flowers). requirements. However, most of the cultivars studied showed chilling requirements ranging from 400 to $500 \mathrm{CU}$, even those considered as late blooming. The last cultivar to complete its chilling requirement was 'Aylés' with 481 CU. Thus, the general pattern, in the Ebro Central Valley, is that chilling requirement completion in almond happens during the first $10 \mathrm{~d}$ of December.

The cultivars studied showed heat requirements of between 5500 and 9300 GDH for blooming. Thus, cultivars having similar chilling requirements may have very different heat requirements, as shown in Fig. 4. Consequently, blooming date is mostly related to the heat requirements, which show in almond a wider range of variability. The cultivars with the lowest heat requirements were 'Constantini' (5345 GDH), 'Pou de Felanitx' (5419 GDH), and 'Desmayo Largueta' (5458 GDH). The cultivars with the highest heat requirements were 'Primoskij', 'Titan', 'Yaltinskij', 'Ferralise', 'Bertina', 'Lauranne', 'Moncayo', 'Tardive de la Verdière', and 'Felisia' (from 8434 to 9352 GDH).

It is also evident that the Spanish cultivars Felisia, Moncayo, Guara, Cambra, Aylés, and Masbovera, and the French cultivars Ferragnès, Ferralise, and Lauranne, obtained in breeding programs, show high heat requirements and occupy the upper right section of Fig. 2, whereas traditional cultivars, such as 'Desmayo Largueta', 'Marcona', 'Ramillete', 'Constantini', 'Pou de Felanitx', and 'Ne Plus Ultra', showed lower heat requirements and occupy the lower left section of Fig. 4.

Some cultivars, such as 'Tardive de la Verdière', 'Rachele', 'Nonpareil', 'Primorskij', 'Lauranne', and 'Felisia', have low chilling requirements together with high heat requirements. On the contrary, other cultivars, such as 'Chellastone', 'Desmayo Rojo', 'Rof', 'Ne Plus Ultra', 'Alzina', and 'Blanquerna', have high chilling requirements together with low heat requirements. These estimations agree with those of Tabuenca et al. (1972) for the cultivars also included in their study. Andrés and Durán (1999) have observed a similar situation in apricot and have pointed out that the coincidence of blooming of several cultivars does not mean that their chilling and heat requirements would be of the same level. This circumstance is taking place with the almond cultivars Constantini and Desmayo Largueta (Table 3). The independent examination of the chilling and heat requirements of two cultivars may obviate the mistake of correlating their thermal requirements for blooming whether their blooming coincides or not. 


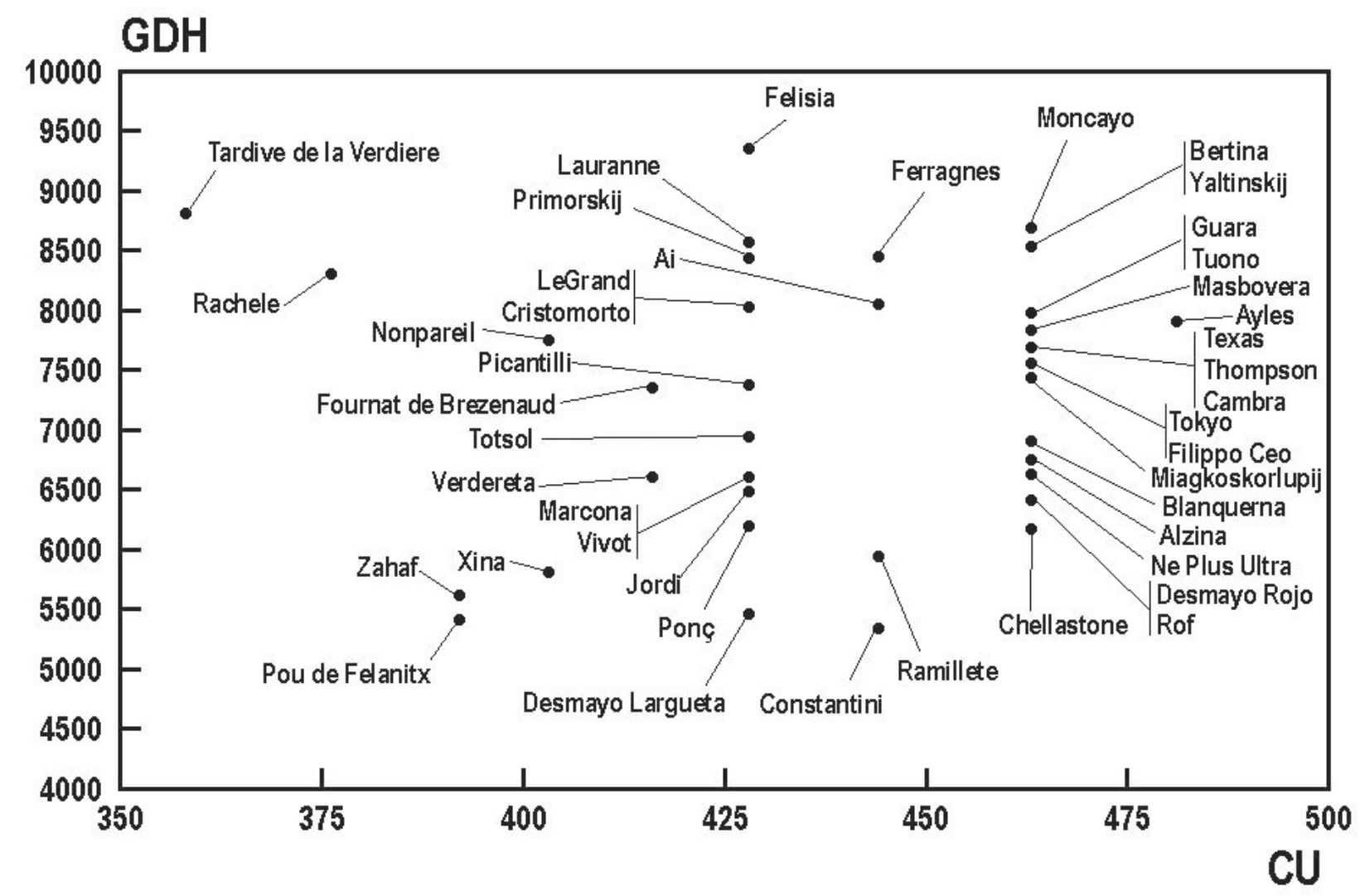

Fig. 4. Distribution of the almond cultivars studied by their chilling requirements [chilling units (CU)] and heat requirements [growing degree hours in Celsius degrees $(\mathrm{GDH})]$.

VALIDATION OF THE MODEL. The model was tested in the 2001-02 season, thus with data not included in the development of the model. The linear regression without intercept of the predicted and observed blooming dates (Table 4) was highly significant, with both a slope and a regression coefficient close to 1 (Fig. 5).

More almond cultivars than before have been studied with this model. The classical studies of almond chill and heat requirements were made with the method of bud dry weight increase and mostly included cultivars with no interest at present (Tabuenca, 1972; Tabuenca et al., 1972). Furthermore, the requirements were not quantified, but their magnitude was rated, thus making comparisons even more difficult. When chilling requirements were quantified (Tabuenca, 1975), they were measured as hours under different temperature thresholds and cannot be compared with CU of Utah Model (Richardson et al., 1974). Besides, the results obtained with this method from a single year are not reliable (Tabuenca, 1972, 1975). However, there is an agreement in the order of chilling requirements here obtained with the common cultivars of Tabuenca et al. (1972).

Modern estimations of almond chilling and heat requirements were made in warmer climates than Zaragoza (Egea et al., 2003; Rattingan and Hill, 1986, 1987). Therefore, in spite of the common use of the Utah model, comparisons between results are difficult due to both the difference on the date of chill accumulation onset and the climatic effects. Thus, Egea et al. (2003) emphasized the major effect of chilling requirements on determining blooming dates, probably due to the difficult determination of dormancy in mild climates (Cook and Jacobs, 2000). Besides, in the cold climate of Zaragoza, where chilling is quickly accomplished, the possible interactive control of chilling and heating (Sparks, 1993) might be much less important.
A major coincidence is observed with the results of Rattingan and Hill (1986 and 1987) than with those of Egea et al. (2003), which were obtained with the method of bud dry weight increase in a single year. Rattingan and Hill (1986) found a low variability for chilling requirements ( 220 to $350 \mathrm{CU}$ ) and a larger variability for heat requirements (5300 to $9000 \mathrm{GDH})$, pointing to a major effect of the heat requirements on determining the blooming date, as we have also observed. As in our work, estimations were made with the statistical computation of temporal series of data and the observation of whole trees in their actual environment during several seasons.

TEMPERATURE REQUiREMENTS AND BLOOMING DATE. In the cold climatic conditions of Zaragoza, heat requirements are more important than chilling requirements to regulate the blooming date in almond due to the early satisfaction of chilling, mostly in early December. The daily average of chill and heat accumulation is of $18.7 \mathrm{CU}$ and $72.8 \mathrm{GDH}$ during the period from $15 \mathrm{Nov}$. to 15 Feb. (Fig. 6). Consequently, blooming date depends more on the climatic conditions of the final period of bud development because the heat accumulation during December is very small (Fig. 6), showing its minimum at the end of December. In Spring 1994, 1995, and 1997, the previous December showed mild temperatures and induced a general advance of blooming dates. The opposite situation was observed in Spring 1996 and 1999, with very cold temperatures in the previous December resulting in a general blooming delay. Thus, the latest blooming cultivars are those with the highest heat requirements (Table 3 ). However, the larger dispersion of blooming dates is produced by the occurrence of low temperatures during the second fortnight of February, when some cultivars have already opened $90 \%$ of the flowers and others have not yet started to bloom. This behavior was already 
Table 4. Predicted and observed blooming dates in 2002 for the almond cultivars studied.

\begin{tabular}{|c|c|c|c|c|c|c|}
\hline \multirow[b]{2}{*}{ Cultivar } & \multicolumn{4}{|c|}{ Theoretical data } & \multirow{2}{*}{$\begin{array}{c}\text { Actual } \\
\text { blooming date } \\
\left(F^{50}\right)^{\mathrm{x}}\end{array}$} & \multirow[b]{2}{*}{ Difference } \\
\hline & $\mathrm{CU}^{2}$ & $\begin{array}{l}\text { Endodormancy } \\
\text { breaking date }\end{array}$ & $\mathrm{GDH}^{\mathrm{y}}$ & $\begin{array}{c}\text { Predicted } \\
\text { blooming date }\end{array}$ & & \\
\hline Pou de Felanitx & 403 & 27 Nov. & 5427 & $14 \mathrm{Feb}$ & $18 \mathrm{Feb}$. & -4 \\
\hline Constantini & 454 & 1 Dec. & 5460 & $20 \mathrm{Feb}$. & $20 \mathrm{Feb}$ & 0 \\
\hline Zahaf & 402 & 27 Nov. & 5692 & $18 \mathrm{Feb}$. & $20 \mathrm{Feb}$ & -2 \\
\hline Desmayo Largueta & 428 & 29 Nov. & 5545 & $19 \mathrm{Feb}$. & $21 \mathrm{Feb}$ & -2 \\
\hline Xina & 403 & 27 Nov. & 5931 & $20 \mathrm{Feb}$. & $23 \mathrm{Feb}$ & -3 \\
\hline Ponç & 428 & 29 Nov. & 6400 & $24 \mathrm{Feb}$. & $23 \mathrm{Feb}$. & 1 \\
\hline Chellastone & 468 & 2 Dec. & 6278 & $25 \mathrm{Feb}$. & $24 \mathrm{Feb}$ & 1 \\
\hline Ramillete & 454 & $1 \mathrm{Dec}$. & 5998 & $23 \mathrm{Feb}$. & $25 \mathrm{Feb}$ & -2 \\
\hline Vivot & 428 & 29 Nov. & 6703 & $26 \mathrm{Feb}$ & $25 \mathrm{Feb}$ & 1 \\
\hline Nec Plus Ultra & 468 & 2 Dec. & 6414 & $24 \mathrm{Feb}$ & $26 \mathrm{Feb}$ & -2 \\
\hline Blanquerna & 468 & 2 Dec. & 6949 & $1 \mathrm{Mar}$ & $27 \mathrm{Feb}$ & 2 \\
\hline Desmayo Rojo & 468 & 2 Dec. & 6596 & $27 \mathrm{Feb}$. & $27 \mathrm{Feb}$ & 0 \\
\hline Jordi & 428 & 29 Nov. & 6567 & $25 \mathrm{Feb}$ & $27 \mathrm{Feb}$ & -2 \\
\hline Totsol & 428 & 29 Nov. & 7068 & $28 \mathrm{Feb}$ & $27 \mathrm{Feb}$ & 1 \\
\hline Verdereta & 416 & 28 Nov. & 6719 & $25 \mathrm{Feb}$. & $28 \mathrm{Feb}$. & -3 \\
\hline Fournat deBrézenaud & 416 & 28 Nov. & 7390 & 1 Mar. & 1 Mar. & 0 \\
\hline Rof & 468 & 2 Dec. & 6596 & $27 \mathrm{Feb}$. & $1 \mathrm{Mar}$. & -2 \\
\hline Marcona & 428 & 29 Nov. & 6703 & $26 \mathrm{Feb}$. & 2 Mar. & -4 \\
\hline Alzina & 468 & 2 Dec. & 6779 & $28 \mathrm{Feb}$ & 3 Mar. & -3 \\
\hline Guara & 468 & 2 Dec. & 8001 & 9 Mar. & 3 Mar. & 3 \\
\hline Miagkoskorlupij & 468 & 2 Dec. & 7521 & 6 Mar. & 3 Mar. & 3 \\
\hline Filipo Ceo & 468 & 2 Dec. & 7685 & 7 Mar. & 4 Mar. & 5 \\
\hline Nonpareil & 403 & 27 Nov. & 7918 & 5 Mar. & 4 Mar. & 1 \\
\hline Picantilli & 428 & 29 Nov. & 7481 & 4 Mar. & 4 Mar. & 0 \\
\hline Texas & 368 & 2 Dec. & 7863 & 8 Mar. & 5 Mar. & 3 \\
\hline Cambra & 468 & 2 Dec. & 7863 & 8 Mar. & 6 Mar. & 2 \\
\hline Rachele & 383 & 26 Nov. & 8308 & 8 Mar. & 6 Mar. & 2 \\
\hline Tuono & 468 & 2 Dec. & 8001 & 9 Mar. & 6 Mar. & 3 \\
\hline Aylés & 487 & 3 Dec. & 7951 & 9 Mar. & 7 Mar. & 2 \\
\hline Tokyo & 468 & 2 Dec. & 7863 & 8 Mar. & 7 Mar. & 1 \\
\hline Cristomorto & 428 & 29 Nov. & 8152 & 8 Mar. & 8 Mar. & 0 \\
\hline Masbovera & 468 & 2 Dec. & 7863 & 8 Mar. & 8 Mar. & 0 \\
\hline Thompson & 468 & 2 Dec. & 7863 & 8 Mar. & 8 Mar. & 0 \\
\hline Aï & 454 & 1 Dec. & 8082 & 9 Mar. & 9 Mar. & 0 \\
\hline Ferragnès & 454 & 1 Dec. & 8082 & 9 Mar. & 9 Mar. & 0 \\
\hline Lauranne & 428 & 29 Nov. & 8671 & 11 Mar. & 9 Mar. & 2 \\
\hline LeGrand & 428 & 29 Nov. & 8152 & 8 Mar. & 9 Mar. & -1 \\
\hline Bertina & 468 & 2 Dec. & 8587 & 12 Mar. & 11 Mar. & 1 \\
\hline Tardive de la Verdière & 365 & 25 Nov. & 8862 & 10 Mar. & 11 Mar. & -1 \\
\hline Moncayo & 468 & 2 Dec. & 8760 & 13 Mar. & 12 Mar. & 1 \\
\hline Primorskij & 428 & 29 Nov. & 8468 & 10 Mar. & 12 Mar. & -2 \\
\hline Yaltinskij & 468 & 2 Dec. & 8587 & 12 Mar. & 12 Mar. & 0 \\
\hline Titan & 454 & 1 Dec. & 8463 & 11 Mar. & 13 Mar. & -2 \\
\hline Felisia & 428 & 29 Nov. & 9363 & $15 \mathrm{Mar}$. & $15 \mathrm{Mar}$. & 0 \\
\hline
\end{tabular}

${ }^{2}$ Chilling units.

${ }^{y}$ Growing degree hours in Celsius degrees.

${ }^{x}$ Anthesis of $50 \%$ of the flowers. observed by Chandler and Brown (1951) when studying almond bloom in California.

Another cause for blooming dispersion in almond could also be the base temperature for the flower bud development, which can be different not only depending on the species (Rattigan and Hill, 1987; Richardson et al., 1975), but also on the cultivars within a species, as has been observed for the progression of blooming in almond (Bernad and Socias i Company, 1995; DeGrandi-Hoffman et al., 1996; Hill et al., 1985). In addition, each cultivar could react in a different way to occasional extreme temperatures or to a sudden alternation of cold and warm temperatures, a typical phenomenon occurring during the spring in temperate climates (Couvillon and Erez, 1985; Erez and Couvillon, 1987), far away from any model of quantification of chilling and heat requirements.

Concluding REMarks. The estimation of the mean date of endodormancy to ecodormancy transition of a cultivar by the model of correlation coefficients between the winter temperatures of periods of 15 or $20 \mathrm{~d}$ and the dates of full bloom is very useful and reliable to calculate its chilling and heat requirements. With this method it is possible to assess the requirements of a great number of cultivars and to single out those having extreme values. These cultivars can be used as parents in a breeding program for late bloom (Socias i Company et al., 2003) from a more reliable point of view because the selection based only on the blooming time does not ensure the largest requirements for both chilling and heat. Cultivars showing high heat requirements may be adapted to a wider spectrum of environments and may produce good crops even in years when or sites where there is a limited chilling accumulation (Citadin et al., 2001). Cultivars with a combination of high chilling and heat requirements will have a stable late bloom in all conditions, although demanding environments where their chilling requirements could be accomplished in order to obtain good yields.

Another application of the chilling and heat estimations for different almond cultivars may be the planting design when cross-pollination is needed. Not only cross-compatible and simultaneously blooming cultivars must be chosen, but also cultivars with similar chilling and heat requirements in order to obtain a maximum overlapping of the blooming period independently of the temperature regime before blooming, thus optimizing the possibilities of cross-pollination. 


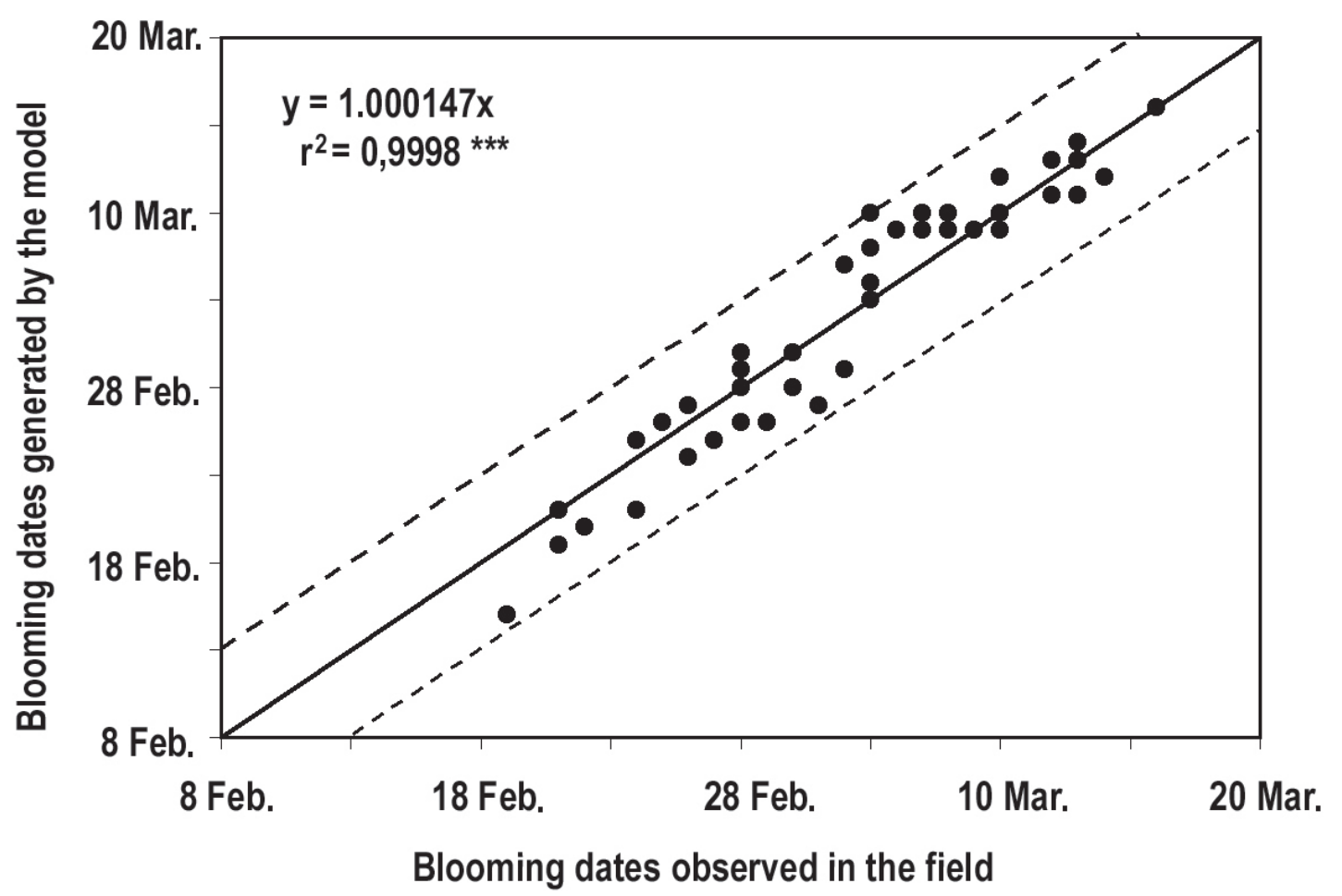

Fig. 5. Linear regression between the predicted and observed blooming dates in 2002. Broken lines mark the interval of $\pm 5 \mathrm{~d}$. *** Significance of the regression at $P<0.001$.

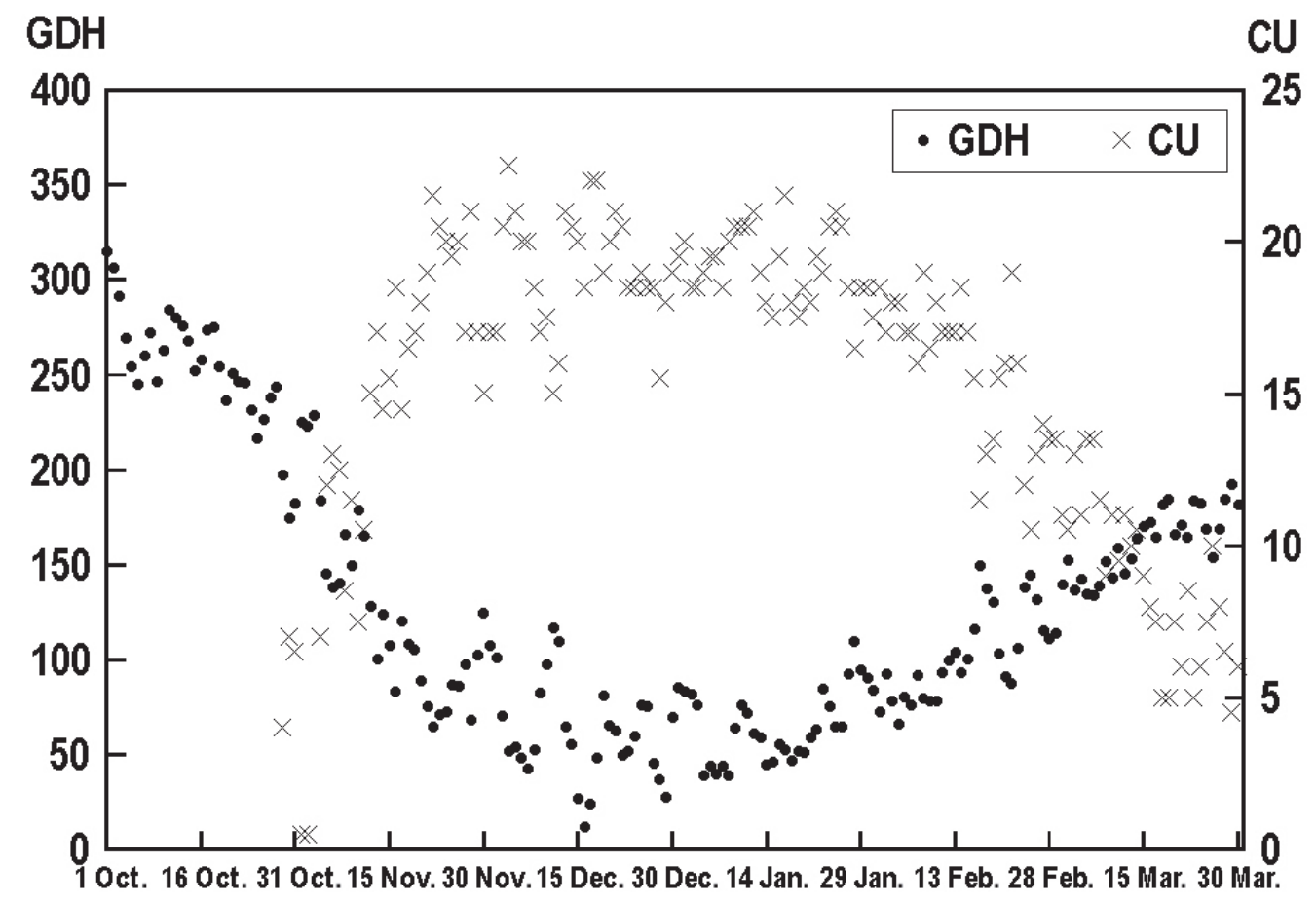

\section{Date}

Fig. 6. Mean daily chill units (CU) and growing degree hours in Celsius degrees (GDH) for the period 1994-2000 at Zaragoza (Spain). 


\section{Literature Cited}

Andrés, M.V. and J.M. Durán. 1999. Cold and heat requirements of the apricot tree (Prunus armeniaca L.). J. Hort. Sci. Biotechnol. 74:757-761.

Ashcroft, G.L., E.A. Richardson, and S.D. Seeley. 1977. A statistical method of determining chill unit and growing degree hour requirements for deciduous fruit trees. HortScience 12:347-348.

Bernad, D. and R. Socias i Company. 1995. Characterization of some self-compatible almonds. II. Flower phenology and morphology. HortScience 30:321-324.

Brown, D.S. and J.F. Abi-Fadel. 1953. The stage of development of apricot flower buds in relation to their chilling requirements. Proc. Amer. Soc. Hort. Sci. 61:110-118.

Brown, D.S. and F.A. Kotob. 1957. Growth of flower buds of apricot, peach and pear during the rest period. Proc. Amer. Soc. Hort. Sci. 69:158-164.

Chandler, J.L. and D.S. Brown. 1951. Deciduous orchards in California winters. Calif. Agr. Ext. Serv. Circ. 179.

Citadin, I., M.C.B. Raseira, F.G. Herter, and J.B. Silva. 2001. Heat requirement for blooming and leafing in peach. HortScience 36:305-307.

Cook, N.C. and G. Jacobs. 2000. Progression of apple (Malus $\times$ domestica Borkh.) bud dormancy in two mild winter climates. J. Hort. Sci. Biotechnol. 75:233-236.

Couvillon, G.A. and A. Erez. 1985. Effect of level and duration of high temperatures on rest completion in peach. J. Amer. Soc. Hort. Sci. 110:579-581.

Dennis, F.G. 2003. Problems in standardizing methods for evaluating the chilling requirements for the breaking of dormancy in buds of woody plants. HortScience 38:347-350

DeGrandi-Hoffman, G., R. Thorp, G. Loper, and D. Eisikowitch. 1996. Describing the progression of almond bloom using accumulated heat units. J. Appl. Ecol. 33:812-818.

Egea, J., E. Ortega, P. Martínez-Gómez, and F. Dicenta. 2003. Chilling and heat requirements of almond cultivars for flowering. Environ. Expt. Bot. 50:79-85.

Erez, A. and G.A. Couvillon. 1987. Characterization of the influence of moderate temperatures on rest completion in peach. J. Amer. Soc. Hort. Sci. 112:677-680.

Felipe,A.J. 1977. Épocas de floración de variedades de almendro. Anales del Instituto Nacional de Investigaciones Agrarias, Serie Producción Vegetal 7:105-112.

Freeman, M.W. and G.C. Martin. 1981. Peach floral budbreak and abscisic acid content as affected by mist, light and temperature during rest. J. Amer. Soc. Hort. Sci. 106:333-336.

Guerriero, R., R. Viti, P. Monteleone, and M. Gentili. 2002. La valutazione della dormienza nell'albicocco: tre metodi a confronto. Frutticoltura 64(3):73-77.
Hill, S.J., D.W. Stephenson, and B.K. Taylor. 1985. Almond pollination studies: Pollen production and viability, flower emergence and crosspollination tests. Aust. J. Expt. Agr. 25:697-704.

Hoshmand, A.R. 1988. Statistical methods for agricultural sciences. Timber, Portland, Ore.

Kester D.E. and T.M. Gradziel. 1996. Almonds, p. 1-97. In: J. Janick and J.N. Moore (eds.). Fruit breeding. vol. 3. Wiley, New York.

Kleijnen, J.P.C. 1999. Validation of models. Statistical techniques and data availability, p. 647-654. In: P.A. Farrington, H.B. Nembhard, D.T. Sturrock, and G.W. Evans (eds.). Proc. 31st Winter Simulation Conf. ACM Press, New York.

Lamp, B.M., J.H. Connell, R.A. Duncan, M. Viveros, and V.S. Polito. 2001. Almond flower development: Floral initiation and organogenesis. J. Amer. Soc. Hort. Sci. 126:689-696.

Lang, G.A., J.D. Early, G.C. Martin, and R.L. Darrell, 1987. Endo-, para-, and ecodormancy: Physiological terminology and classification for dormancy research. HortScience 22:371-377.

Rattigan, K. and S.J. Hill. 1986. Relationship between temperature and flowering in almond. Aust. J. Expt. Agr. 26:399-404.

Rattigan, K. and S.J. Hill. 1987. Relationship between temperature and flowering in almond: Effect of location. Aust. J. Expt. Agr. 27:905-908.

Richardson, E.A., S.D. Seeley, and D.R. Walker. 1974. A model for estimating the completion of rest for 'Redhaven' and 'Elberta' peach trees. HortScience 9:331-332.

Richardson, E.A., S.D. Seeley, D.R. Walker, J.L. Anderson, and G.L. Ashcroft. 1975. Phenoclimatography of spring peach bud development. HortScience 10:236-237

Socias i Company, R. and A.J. Felipe. 1992. Almond: A diverse germplasm. HortScience 27:717-718, 863.

Socias i Company, R., A.J. Felipe, and J. Gómez Aparisi. 2003. Almond bloom in a changing climate. J. Amer. Pomol. Soc. 57:89-92.

Sparks, D. 1993. Chilling and heating model for pecan budbreak. J. Amer. Soc. Hort. Sci. 118:29-35.

Tabuenca, M.C. 1972. Necesidades de frío invernal en almendro. Anales Aula Dei 11:325-329.

Tabuenca, M.C. 1975. Evaluación de las necesidades de frío para salir del reposo de variedades de almendro. Anales Aula Dei 13:208-217.

Tabuenca, M.C. 1980. Necesidades de frío invernal y exigencias de calor previas a la floración de variedades de ciruelo europeo. Anales Aula Dei 15:148-159.

Tabuenca, M.C. and J. Herrero. 1966. Influencia de la temperatura en la época de floración de frutales. Anales Aula Dei 8:115-153.

Tabuenca, M.C., M. Mut, and J. Herrero. 1972. Influencia de la temperatura en la época de floración de variedades de almendro. Anales Aula Dei 11:378-395.

Westwood, N.H. 1978. Temperate-zone pomology. W.H. Freeman, San Francisco. 